\title{
Martínez OJeda, Beatriz (ed.) Cuadernos de Traducción. Córdoba: UCOPress, 2020, 208 pp. ISBN 978-84-9927-549-9
}

Este volumen, editado por la Dra. Beatriz Martínez Ojeda y publicado por UCOPress, es una recopilación de material docente destinado a estudiantes de Traducción e Interpretación, así como a profesionales de la misma. Recoge entre sus páginas capítulos dedicados a diversas ramas de la traducción: humanístico-literaria, jurídico-económica, audiovisual, e incluye también un capítulo de introducción a distintas herramientas profesionales. Los distintos capítulos aúnan en sus páginas contenidos teóricos, que aclaran conceptos básicos, así como debates de cada rama, seguidos de ejercicios prácticos en tres idiomas (inglés, francés y alemán) que permiten asentar los conocimientos adquiridos. Tal y como señala María Luisa Rodríguez en el prólogo, los autores que firman los respectivos capítulos, profesionales a los que les avala los años de experiencia docente en distintos niveles de aprendizaje, hacen del presente un manual variado en temática capaz de aportar conocimiento a los estudiantes, pero también puede servir de inspiración a otros docentes para incorporarlos en sus propias clases.

En primer lugar, nos encontramos con el capítulo titulado «Introducción a la Traducción Audiovisual alemán-español», a cargo de Pilar Castillo Bernal. En él, encontramos primero una definición de la rama, así como un primer ejercicio práctico de traducción DE>ES. El capítulo continúa con una caracterización de sus particularidades y de los distintos códigos de significación audiovisuales; junto con una breve historia del surgimiento y evolución de los estudios de Traducción Audiovisual (TAV), cuyo auge investigador lo encontramos en la década de los 90, y que llega hasta la actualidad. Si bien al principio la especialidad surgió ligada a las producciones fílmicas y las series de televisión, en la actualidad no está restringida solo a ellas, y abarca ámbitos profesionales muy diversos, como «el subtitulado para plataformas de streaming, subtitulado en directo o para la televisión, localización de videojuegos, subtitulado automático, traducción para la accesibilidad e interpretación en museos, representaciones o producciones, etc.». Debido a esta amplitud, el capítulo se centra en desglosar las distintas modalidades de traducción audiovisual, así como los factores que juegan un papel en la elección de una forma u otra según los distintos géneros audiovisuales y las dificultades que conlleva esta especialidad. Se trata de un capítulo bastante práctico, en el que encontramos ejercicios para clasificar algunos fragmentos según las modalidades que en ellos se emplean y hasta un encargo de traducción para presupuestar.

El siguiente capítulo corresponde a la rama humanístico-literaria, y en él Soledad Díaz Alarcón nos habla de la «Didáctica de la traducción literaria: 
perspectivas y competencias de aprendizaje». ¿Es posible traducir literatura? $Y$ de serlo, ¿nos encontraríamos en el ámbito del arte o de la ciencia? Para responder a estas preguntas, la autora primero habla de las particularidades que entrañan tanto el texto como el lenguaje literarios. El texto literario se conforma como «un sistema de comunicación especial en el que intervienen diversos factores que lo diferencian de otros actos de comunicación». Estos factores conforman la «literariedad», concepto acuñado por el lingüista Roman Jakobson, y es la cualidad que haría que un mensaje o texto fuese literario, gracias a una serie de marcas lingüísticas y estructurales inherentes a estos textos, como la ficcionalidad o el predominio de la función estética. La complejidad de la traducción literaria es evidente, porque la obra traducida ha de causar en el lector el mismo efecto que haría el original, como dicen Nida y Taber, y debe responder a una serie de exigencias lingüísticas, estéticas, temporales y culturales, aunando en sí la equivalencia formal y la equivalencia dinámica. Díaz enumera así mismo los distintos estudios teóricos dedicados a la traducción literaria, caracterizándolos brevemente y realizando una breve evolución histórica de ellos, para después realizar un repaso de los diversos enfoques que se dan en la didáctica de la enseñanza de esta modalidad de traducción, deteniéndose en los de Wuilmart, Bravo Utrera y García Álvarez. Es a partir de los distintos enfoques y métodos, que la autora realiza una propuesta metodológica para llevar al aula.

El tercer capítulo está dedicado a las «Herramientas Profesionales para la Traducción", y está a cargo de María del Carmen López Ruiz. Se trata de un apartado esencial, pues dicha asignatura conforma el primer acercamiento de los traductores en ciernes hacia su futuro entorno laboral. Se centra en las herramientas de Traducción Asistida por Ordenador (TAO), así como en bases de datos y memorias de traducción, todas ellas vitales para realizar un trabajo lo más eficiente posible. Sirve también este capítulo para reivindicar la importancia de la figura del traductor en el debate actual sobre la traducción automática, pues las máquinas se han mostrado incapaces de captar y transmitir la totalidad de significados, derivados, entre otros, del contexto. El apartado incluye un listado de programas TAO y sus características principales, destacando Trados Studio (SDL), Memo Q y Wordfast; y también hay espacio en él para herramientas de TAV (Traducción Audiovisual) y para la localización de páginas web, software e imágenes. El capítulo finaliza con unos apuntes sobre el funcionamiento de las empresas de traducción, y las tareas con las que se encontrarán los estudiantes al incorporarse al mercado laboral: presupuestos, facturas, gestión de proyectos, etc.

El capítulo número cuatro, a cargo de Beatriz Martínez Ojeda, es el segundo de un total de tres dedicado a la rama humanístico-literaria de la 
recopilación, «Metodología de análisis traductológico en los textos literarios: el caso de la traducción poética (francés-español)». A lo largo de los años, han surgido nuevas modalidades de traducción que, en el ámbito universitario, han dejado en un segundo lugar a la traducción literaria y especialmente la poética. Con el fin de revitalizar estas modalidades, los teóricos de la traducción han optado por el "análisis traductológico», que consiste, a grandes rasgos, en la confrontación entre el texto original y el texto traducido, pudiendo incluso darse el caso de poner en diálogo diversas traducciones a una misma lengua de un texto único. Dicho análisis puede realizarse sobre una traducción propia o ajena, y en ambos casos nos encontramos con resultados distintos. Al analizar una traducción ajena, solo disponemos del resultado final, no conocemos ni el proceso ni las decisiones que han debido ser tomados; en cambio, el análisis de una traducción propia, es más rico, ya que atañe al proceso mismo de traducción, más que al resultado, y la motivación detrás de cada decisión. Es el objeto pues de este estudio el de definir y sistematizar un método traductológico aplicado a la traducción poética. Para ello, el paso primero sería analizar el texto en la lengua origen, y determinar el tipo de estrofa y rima, y demás características del mismo. La autora recoge también en el cuerpo de su exposición las taxonomías que guían la clasificación de errores, pues el objetivo del análisis es determinar la calidad de la traducción. Martínez Ojeda propone un análisis traductológico articulado en cinco niveles: ortotipográfico, fonético-fonológico, morfosintáctico, léxico-semántico y pragmático-cultural.

En «Teoría y práctica del subtitulado: caso práctico basado en la traducción (inglés-español) de la película Juno», que supone el segundo del trabajo dedicado a la traducción audiovisual, María del Mar Ogea Pozo centra su atención sobre el subtitulado y su práctica en España, partiendo para ello de un caso práctico, que aporta además un enfoque muy didáctico que puede ser adaptado por otros docentes en sus clases. En el primer apartado del capítulo, Ogea nos brinda varias definiciones de algunos autores sobre el subtitulado, para enumerar las características que diferencian a esta modalidad de otras de la rama audiovisual, y se centra en algunos aspectos como el formato y el espacio, el tiempo y velocidad de lectura y la sincronía. En este capítulo encontramos una serie de ejercicios prácticos, de la película Juno, e incluye al final del mismo sugerencias de solución de dichos ejercicios, ya que en estos casos los lectores pueden optar por un amplio abanico de versiones. Uno de los consejos claves que da la autora es el de erradicar la idea de que el subtítulo sea una transcripción de la banda sonora de la película o serie, ya que es necesario un ajuste preciso para no interferir en la experiencia del espectador, así como una sintetización, por medio de estrategias de condensación u omisión. 
Por su parte, María Luisa Rodríguez Muñoz y Martha Gaustad, en «Aspectos Traductológicos Ejemplificados: casos prácticos para llevar el Manual de Traducción y Traductología en la piel», analizan los prejuicios y presupuestos con los que los alumnos llegan a la carrera. Para ello, nos presentan un capítulo muy práctico y dinámico, basado en sus años de docencia de Traductología, en el que nos hablan de los distintos ejercicios que ponen en práctica con sus alumnos y analizan las respuestas más comunes que dan. Realizan pues una propuesta didáctica y metodológica para acercar la Traductología a los alumnos de nuevo ingreso, unos ejercicios enriquecedores tanto para el alumnado que lea el presente como complemento a su formación, como para los docentes, que pueden encontrar aquí ideas para llevar a cabo en sus propias clases. Encontramos ejercicios de distinta clase, y que hacen referencia a distintos tipos de traducción, incluida la traducción de arte, aspecto que no ha sido tratado en otros capítulos del presente volumen, y que resulta especialmente llamativo para los alumnos. Con todos estos ejercicios que nos plantean, consiguen que los alumnos o lectores lleguen a comprender o identificar las características definitorias de la traductología, a través de un método inductivo.

Nos acercamos ya al final del volumen, y nos encontramos con el último de los tres capítulos que hablan de la rama audiovisual de la traducción. El encargado de este último es Francisco Rodríguez Rodríguez y en él tenemos una «Introducción al doblaje francés-español». Es un capítulo muy ilustrativo, puesto que por medio de ejercicios prácticos supone la entrada al mundo del doblaje, que hasta ahora no había sido tratado en el manual. En sus páginas, Rodríguez Rodríguez analiza distintos conceptos fundamentales del doblaje, tales como el de sincronía, que son necesarios para que el espectador, experto o no en el arte del doblaje, tenga una buena percepción y valoración del mismo; o el concepto de guion, y su carácter de texto híbrido, que persigue dentro de una oralidad prefabricada lograr el máximo efecto de naturalidad posible. La traducción del guion es un paso fundamental para la realización del doblaje, y el autor revisa aquí los puntos y aspectos fundamentales a tener en cuenta para su correcta adaptación a la versión doblada. Finalmente, nos encontramos con los pasos que se siguen en el proceso del doblaje, a través de los cuales se analizan los distintos componentes y agentes que toman parte en él (director artístico, director de doblaje, actores, ajustadores, traductores...), así como la relación con el cliente.

Llegamos al último capítulo del volumen, «Introducción al lenguaje jurídico (EN-FR-ES), en el que María Azahara Veroz González nos habla de la rama jurídico-económica de la traducción. En él, la autora caracteriza el texto jurídico, que destaca por «su opacidad y formalidad en el registro, que 
utiliza un léxico conservador y arcaizante y en el que aparecen neologismos". Sigue en el capítulo una caracterización de los distintos géneros que se dan dentro de la rama. Géneros que, por otra parte, no están exentos de hibridación, por lo que a menudo los estudiantes pueden encontrarse un texto con características de más de un género, lo que aumenta la complejidad de la traducción. Es por ello que la autora resalta la necesidad de formarse y profundizar ampliamente en los distintos subgéneros antes de enfrentarse a ellos para su traducción.

No quisiera pasar por alto los epígrafes bibliográficos que aparecen al final de cada capítulo, pues son muy ricos y extensos, y dotan tanto a los estudiantes como a los profesionales con numerosos recursos. Son además epígrafes que sirven para demostrar la sólida base documental sobre la que se asientan la mayoría de las propuestas planteadas en el volumen, y que son el complemento ideal de los distintos casos prácticos y ejercicios planteados a lo largo del manual.

En definitiva, el presente volumen muestra con éxito los conceptos fundamentales de las ramas humanístico-literaria, jurídico-económica y audiovisual, así como igualmente aporta distintas propuestas metodológicas, capaces de enriquecer a estudiantes y docentes, así como profesionales, que pueden aplicar dichas propuestas a su labor. Cumple por ello con las expectativas que alumnos y lectores puedan poner en él, y puede resultar muy interesante para todos aquellos que deseen acercarse a las distintas ramas de la traducción.

[María del PILAR Peña Molina] 